\title{
Anacronismos históricos, potenciales políticos: la memoria transnacional de la desaparición en Latinoamérica ${ }^{1}$
}

\author{
Silvana Mandolessi \\ Universidad Católica de Lovaina
}

\begin{abstract}
Resumen:
Este artículo examina el concepto de 'memoria transnacional' y su relevancia para el estudio de la memoria colectiva en el ámbito hispánico. Primero, exploro los términos teóricos usados para referir a una dimensión transnacional de la memoria, tales como 'travelling', 'multidirectional', 'cosmopolitan' o 'globital' memory. Segundo, distingo entre diferentes modos de concebir lo transnacional: como 'condición histórica' o 'perspectiva hermenéutica', 'circulación' o 'negociación'. Por último, luego de evaluar su pertinencia para el análisis del fenómeno de la desaparición en el ámbito hispánico, discuto el carácter legítimo de la apropiación de la figura del desaparecido en otros contextos diferentes del original.
\end{abstract}

Palabras clave: memoria transnacional, memoria colectiva, desaparecido, Argentina, México, España

\begin{abstract}
:
This article examines the concept of 'transnational memory' and its relevance for the study of collective memory in the Hispanic world. First, I explore the terms used to refer to a transnational dimension of memory, such as 'travelling', 'multidirectional', 'cosmopolitan' or 'globital'. Second, I distinguish between different ways of conceiving of the transnational, as a 'historical condition' or 'hermeneutic perspective', as related to an imaginary of 'circulation' or 'negotiation'. Finally, after assessing its relevance for the analysis of the phenomenon of disappearance in the Hispanic world, I discuss the legitimacy of the appropriation of the figure of the 'disappeared' in contexts that differ from the original one.
\end{abstract}

Keywords: transnational memory, collective memory, disappeared, Argentine, Mexico, Spain

En los últimos años, la memoria ha experimentado un 'giro transnacional'. Esto es obvio no solo en el extendido uso del término 'transnacional', sino también en la presencia de términos relacionados que exploran los modos en que la memoria circula entre y más allá de los bordes del estado-nación. Esta característica ha sido concebida como 'multidirectional' (Michael Rothberg), 'global' (Assmann y Conrad), 'cosmopolitan' (Levy y Sznaider), 'travelling' (Astrid Erll) o 'globital' (Anna Reading), por nombrar solo los más representativos. La proliferación de conceptos señala algo bastante obvio: más allá de una conceptualización amplia en la que estos términos coinciden, hay muchas maneras en que la transnacionalización de la memoria puede ser entendida.

\footnotetext{
${ }^{1}$ Este proyecto ha recibido financiación del European Research Council, en el Programa Marco de Investigación e Innovación de la Unión Europea Horizonte 2020 ("Digital Memories" Grant Agreement $\mathrm{N}^{\circ}$ 677955).
} 
En otras palabras, 'transnacional' denomina diversos enfoques, además de intersectarse con otras discusiones recientes tales como los debates en torno al impacto de los medios digitales sobre la memoria. En consecuencia, la memoria transnacional — definida como una entidad — o la transnacionalización de la memoria — definida como un proceso, un estado de la cuestión o incluso una suerte de corrección a la estrechez teórica del foco en lo nacional- plantea preguntas no solo sobre conceptos, sino también, y para mí de crítica importancia, preguntas metodológicas, acerca de cómo transformar la categoría en una herramienta metodológica útil.

En lo que sigue quisiera discutir en primer lugar los problemas involucrados en la dimensión transnacional de la memoria, y en un segundo momento, esbozar su pertinencia para el ámbito específico del mundo hispano.

\section{Memoria transnacional:}

\section{'condición histórica' y 'perspectiva hermenéutica'}

En un sentido amplio y no restringido a la memoria, 'transnacional' se refiere a una condición histórica: la globalización. El escenario es bien conocido: desde los años 90 vivimos en una era de aceleración de la globalización (Appadurai) descripta por Vertovec como "the world spanning intensification of interconnectedness" (Vertovec 54). Esta interconexión es alimentada por la movilidad de sujetos, pero sobre todo por la revolución digital característica de nuestra sociedad post-industrial (Ezra y Rowden 1). Así, la globalización actúa como el entorno, el marco en que la transnacionalidad se desarrolla, aunque esto no implica que la definición y el alcance de lo que entendemos por globalización sea un asunto consensuado.

En los últimos veinte años la teoría de la globalización ha tendido a desarrollarse en 'olas'. Característico de la década del 90 fue un discurso 'hiperglobalista' en el que la globalización aparecía como un fenómeno homogéneo o relativamente unitario a través del cual las diferencias locales eran erosionadas a favor de procesos culturales, sociales y económicos de alcance global. Más recientemente, la teoría de la globalización ha evitado esta visión totalizadora, concibiéndola de una manera mucho más matizada y plural. La globalización no es un proceso único ni necesariamente homogeneizador ni homogéneo; no se desarrolla sin negociaciones ni resistencias, es multidimensional y multidireccional. También es, hasta cierto punto, impredecible, lo que contrarresta el determinismo que, sea desde una visión celebratoria o una apocalíptica, veía a la globalización como un fenómeno incontestable en su desarrollo. David Inglis advierte contra el discurso hiperglobalista que se manifiesta en frases generalizadoras del tipo "vivimos en un mundo global", o en "la era de la globalización". De acuerdo a Inglis, cuando los estudios de memoria giraron su atención hacia lo transnacional, en muchos casos adoptaron acríticamente esas afirmaciones. Reproducir ese discurso lleva a descripciones superficiales y simplificadoras. Inglis señala:

When such glib phrases are used, they can encourage equally superficial understandings of contemporary culture's memory-making capacities, where we all supposedly live in an 'era of forgetting' (Elshtain 2008) or conversely in an 'epoch of remembering' (Olick 
2003). Such broad claims do not help us to understand more precisely the specific mechanisms involved in the relationships between trans-national phenomena and memory phenomena. (Inglis 144)

Ese discurso hiperglobalista también supone que la globalización es un fenómeno totalmente nuevo, sin precedentes. Esto también afecta a la manera en que concebimos lo transnacional, y particularmente en el caso de la memoria. Radicalizar las diferencias entre una era anterior — dominada por la nación — y la actual — transnacional— sugiere que antes no existían, o al menos que no eran tan importantes, los procesos, instituciones y estructuras que trascendían los límites de la nación. Dirigir la atención hacia esas fuerzas en lugar de concentrarse en los procesos de memoria que suceden en el marco de la nación nos lleva a un segundo modo de concebir la memoria transnacional.

Además de referir a un periodo o a una condición histórica, 'transnacional' indica una perspectiva hermenéutica, esto es, la pérdida de supremacía del estado-nación como el foco de análisis. Seigel lo resume en los siguientes términos:

Perhaps the core of transnational history is the challenge it poses to the hermeneutic preeminence of nations. Without losing sight of the "potent forces" nations have become, it understands them as 'fragile, constructed, imagined'. Transnational history treats the nation as one among a range of social phenomena to be studied, rather than the frame of the study itself. (Seigel 63)

Esto es central para los estudios de memoria ya que, como es bien conocido, el área ha estado prioritariamente abocada al análisis de cómo funciona la memoria dentro del marco de la nación. Desde Sobre la memoria colectiva, de Halbwachs, a Cultural Memory, de Jan Assmann, pasando por Les Lieux de Mémoire de Pierre Nora, la memoria ha sido concebida como una propiedad del estado-nación, jugando un rol central en la creación y la pervivencia de una 'comunidad imaginada' (Anderson). En "Travelling Memory" (2011) Astrid Erll ve el foco privilegiado en la nación no solo como "somewhat ideologically suspect" sino también "epistemologically flawed" (8). "Ideologically suspect" porque se vincula a una noción de cultura reificada, que se equivoca al ver que las culturas no son mónadas sino redes. Y "epistemologically flawed" porque hay demasiados fenómenos que quedan fuera del campo de visión en la combinación de comunidad territorial, étnica y nacional que se promovió como el marco principal de la memoria cultural (Erll 8). En el análisis de Erll, la memoria aparece como un fenómeno intrínsecamente transcultural, que no sería por lo tanto un rasgo exclusivo de la globalización. La movilidad que James Clifford subrayó en la cultura, al afirmar que "cultures do not hold still for their portraits", es igualmente válido para la memoria: "The same is true for memory: Memories do not hold still — on the contrary, they seem to be constituted first of all through movement" (11). Esta movilidad constitutiva de la memoria que se construye en base a la circulación transcultural de objetos, prácticas, estructuras y relatos, habría sido soslayada desde el inicio de los 'memory studies', en particular, por uno de sus padres fundadores, Maurice Halbwachs. El concepto de memoria colectiva que propone Halbwachs, al enfatizar el carácter autocentrado de los grupos sociales, oblitera la dimensión transcultural que él mismo reconoce en cambio cuando analiza el nivel individual de la memoria. Este énfasis en la similitud y la homogeneidad es consolidado más tarde por el trabajo de Pierre Nora, que se sostiene sobre un isomorfismo entre territorio, formación social y memoria. En el extremo opuesto 
a esta manera de concebir la memoria ligada a una cultura de bordes delimitados y precisos - 'clear-cut territories' - Erll sitúa a otro de los padres fundadores, a Aby Warburg, recuperándolo para marcar precisamente que existe otra genealogía posible, una fundación alternativa del campo. Fue Warburg quien, en trabajos como la exhibición Mnemonsyne-Atlas o en la reconstrucción sobre la supervivencia de la antigüedad clásica en el arte europeo, eligió poner en primer plano la migración de símbolos a través del espacio y el tiempo, una migración afín, sino idéntica, a la incesante errancia de las prácticas, contenidos y formas que constituye la memoria transnacional. Un enfoque transnacional vendría entonces a corregir esa perspectiva reductiva que habría dominado al campo de estudios de memoria, investigando la transmisión, circulación, mediación y recepción de la memoria entre y más allá de los límites de la nación. Se trataría entonces de recuperar una perspectiva hermenéutica soslayada que siempre ha estado, sin embargo, presente, y que la globalización no haría sino acentuar y poner radicalmente de manifiesto.

Dicho esto, el rango de fenómenos que implica este enfoque es múltiple. ¿A qué nos referimos concretamente cuando hablamos de 'memoria transnacional'? ¿En qué fenómenos mnemónicos nos focalizamos al abordar la memoria 'transnacionalmente'?

\section{Dos formas de concebir la memoria transnacional: 'circulación' y 'negociación'}

Desde mi punto de vista, hay dos formas principales de concebir la dimensión transnacional de la memoria. En la primera, el concepto clave es circulación. En un mundo globalizado, las memorias circulan, se mueven, viajan, entre y más allá de los bordes del estado-nación. Circulación implica que las memorias se forman a través de préstamos y alianzas, a través de transferencias dinámicas, que los caminos que siguen no son rectos. Tienen una 'vida social' (Rigney), se mueven a través del espacio y a través del tiempo. En esa movilidad se transforman para adaptarse a nuevos contextos y para apoyar diferentes reclamos políticos. La idea de movilidad socava el supuesto vínculo indisoluble entre memoria e identidad cultural y en un sentido amplio, el de 'propiedad'.

Esta idea de circulación es central en muchos conceptos, tales como el de 'travelling memory' acuñado por Erll. Erll propone investigar los 'viajes' de la memoria en lugar de los 'sitios'. La memoria puede ser estudiada a través de la reconstrucción de sus rutas: los caminos que ciertas historias, rituales e imágenes han seguido, y no tanto haciendo eco de lo que los grupos sociales definen como sus raíces: los supuestos orígenes incontaminados de la memoria cultural (11). Un enfoque afín, aunque centrado en la dimensión temporal, es el propuesto por Ann Rigney en su estudio sobre la "social (after)-life" de los textos literarios en la memoria cultural. Rigney indaga cómo los textos perviven en el tiempo adquiriendo nuevos sentidos según son recuperados en contextos distantes de su origen. A la manera de la 'supervivencia' de los objetos culturales estudiada por Warburg, los textos transgreden barreras temporales y espaciales para inscribirse como restos, huellas o ruinas productivas en memorias que adquieren siempre la forma de un palimpsesto. Un enfoque en el que también la idea de circulación es central es el propuesto por Michael Rothberg en su libro Multidirectional Memory (2009). Rothberg discute el supuesto de que diferentes grupos compiten por imponer su memoria en el espacio social, y que la lógica que domina esta competencia es de 
'suma-cero', es decir, que si uno logra imponer su reclamo como válido eso siempre resulta en una pérdida del otro, cuya memoria aparecería entonces como menos válida de suscitar reconocimiento. En lugar de una lógica competitiva, Rothberg propone que la memoria de un grupo se crea en un diálogo con otras memorias, de grupos con diferentes experiencias históricas. Por ejemplo, las discusiones públicas sobre el Holocausto pueden desencadenar debates de memoria sobre otros eventos trágicos, como la discusión en Francia sobre el legado de la Guerra de Argelia. Rothberg desmonta la relación íntima entre memoria e identidad. Escribe:

The model of multidirectional memory posits collective memory as partially disengaged from exclusive versions of cultural identity and acknowledges how remembrance both cuts and binds together diverse spatial temporal and cultural sites. (11)

La segunda manera de entender la memoria transnacional es no como circulación, sino como negociación. Esto se vuelve claro en el siguiente ejemplo: a mediados de los 90, Europa lanzó la idea de crear un 'Museo de Europa' que reflejaría las múltiples tradiciones culturales europeas e historias en un espacio común. El proceso de construir una historia transnacional de Europa resultó ser más complejo de lo que se esperaba, y solo en mayo de 2017, luego de ser muchas veces pospuesto, el museo — rebautizado como House of European History - fue finalmente inaugurado. La iniciativa busca construir una historia transnacional de Europa, una capaz de abarcar todos los países. Pero este es el punto donde el proyecto enfrenta el proceso de conciliar memorias conflictivas de eventos claves, respecto a los cuales los países reclaman 'verdades históricas' diferentes, o incluso opuestas. En este caso, 'memoria transnacional' se refiere a una negociación para encontrar una visión común para memorias que exceden el marco del estado-nación. Una 'memoria europea' — si algo así es posible— sería un acuerdo común entre los países europeos que implica no solo superar disputas entre diversos países sino también resolver puntos críticos, tales como el lugar de la memoria del Estalinismo en relación a la memoria del Holocausto.

En otro sentido, es precisamente el Holocausto el ejemplo más notable de la creación de una memoria transnacional, en tanto un símbolo supranacional de memoria en el que todos los europeos — pero no solo los europeos- pueden reconocerse. Levy y Sznaider han investigado la memoria del Holocausto en la era global acuñando el término 'cosmopolitan memory'. Aunque la memoria cosmopolita que encarna el Holocausto no es el resultado de una negociación entre países diferentes, constituye, sin embargo, un acuerdo, un suelo común sobre el que se funda el discurso de los Derechos Humanos, discurso que hoy tiene un alcance global.

Estas dos formas de concebir la memoria transnacional no son opuestas; de hecho, en muchos sentidos interactúan. Sin embargo, señalan imaginarios diferentes: la idea de circulación evoca un imaginario de dispersión, diseminación, desplazamiento, disolución. En contraposición, el proceso de negociación que subyace a las memorias supranacionales refiere a un imaginario de reunión, concentración, emplazamiento, consolidación. 


\section{Memoria transnacional en el área iberoamericana}

Una de las críticas frecuentes que se le hace al enfoque transnacional es que va del espacio acotado y definido del estado-nación al espacio difuso e inabarcable de lo global. En este movimiento, la memoria parece disolverse en una circulación que carece de todo anclaje.

Una respuesta posible: postular como unidad intermedia un área que exceda el territorio acotado de una nación particular pero que como conjunto vincule histórica, lingüística y culturalmente a los diversos países que la integran. En este caso me refiero al área iberoamericana ${ }^{2}$ como una unidad donde es posible observar fenómenos transnacionales sin que estos se disuelvan en el todo inasible de lo global. Focalizados en el estudio de la memoria: ¿qué relevancia tiene un enfoque transnacional para el área iberoamericana? Un enfoque transnacional permite analizar fenómenos que no serían inteligibles si solo observamos la intervención de los actores y la elección de determinadas estrategias en un marco exclusivamente nacional.

Lo que quiero plantear aquí como ejemplo es la relevancia de un estudio transnacional de la desaparición en el área de Latinoamérica y España. ¿Por qué la desaparición como fenómeno y la figura del desaparecido como sujeto particular son relevantes en el área? En primer lugar, porque el fenómeno de la desaparición ha experimentado en Latinoamérica un uso extendido que abarca no solo los países del Cono Sur, sino también Perú, Guatemala, El Salvador, Colombia y México, por nombrar los más representativos. El fenómeno de la desaparición se ha dado en cada caso en contextos diferentes, que incluyen procesos dictatoriales, conflictos armados o 'guerras internas no civiles', como en el caso de México. Sin embargo, contra la diferencia y la especificidad de los contextos nacionales en los que la tecnología represiva de la desaparición tiene lugar, es posible observar cómo las prácticas, las representaciones y las estrategias nacidas de los movimientos de resistencia contra esta práctica, viajan, se reproducen y se adaptan. Nuevas prácticas adquieren sentido a partir de la adopción de representaciones originadas en otros países y cobran sentidos nuevos que no pueden entenderse plenamente sin considerar las apropiaciones transnacionales que participan en su constitución. En este sentido, es posible rastrear préstamos y apropiaciones múltiples, que involucren uno o varios países latinoamericanos. Lo que presento a continuación es solo un ejemplo posible que incluye Argentina, España y México. El recorrido se establece en torno a tres hitos: en primer lugar, Argentina, como país donde la figura del desaparecido es creada y también como el escenario de la 'invención' de prácticas, instituciones y mecanismos centrales en torno a la desaparición. Argentina entonces como un punto inicial, un punto de partida. Esto no significa negar la importancia del fenómeno en el resto de los países del Cono Sur (especialmente Uruguay y Chile) sino otorgar a Argentina, siguiendo la literatura existente, un rol destacado en ciertas estrategias de consolidación y difusión. El segundo hito se da en España, puntualmente, en relación al debate que se origina a comienzos del siglo XXI sobre una 're-lectura' de las víctimas del Franquismo en términos de la figura del desaparecido. El debate, que

\footnotetext{
2 'Iberoamérica' se refiere aquí al territorio conformado por los países latinoamericanos cuya lengua mayoritaria es el español, sumando la inclusión de la Península Ibérica. Se trata de una definición operativa, en el intento de señalar un área común que incluye vínculos históricos, culturales y lingüísticos. Si bien no todas las definiciones de Iberoamérica incluyen la península Ibérica, la RAE la incluye en los usos del término.
} 
ha sido objeto de excelentes investigaciones como las de Francisco Ferrándiz o Ulrike Capdepón, muestra las tensiones originadas en torno a la 'traducción' de la figura a un contexto muy diferente del original. El tercer hito es uno más reciente: el ingreso del término al debate público en México, que sigue al conflicto de la desaparición de los 43 estudiantes de Ayotzinapa el 26 de septiembre de 2014 y que se ubica nuevamente en un marco alejado del de las dictaduras latinoamericanas de los años 70: el marco de la Guerra contra el Narco iniciada en 2006. Dado que, por una cuestión de espacio es imposible analizar producciones concretas, me limito a presentar los vínculos a fin de mostrar por qué es relevante considerar estos casos en conjunto. En el apartado final argumento por qué la 'transnacionalización' del desaparecido no debe ser pensada como 'anacronismo histórico' sino, en cambio, ser analizada en su potencial político.

\section{Hacia una memoria transnacional de la desaparición en el área iberoamericana}

Aunque la desaparición es un método de violencia política que tiene sus raíces en el régimen nazi y es una tecnología represiva ampliamente difundida a nivel mundial, en el área iberoamericana posee una historia particular. El área iberoamericana, conformada por naciones que comparten un lenguaje común y una historia de colonialismo, también compartió una red transnacional de terror en el siglo XX. Las dictaduras implementadas por los países del Cono Sur (Chile, Argentina, Uruguay, Paraguay, Bolivia, y en menor medida Brasil) en los 70 y 80 fueron el resultado de una red transnacional de represión conocida como Plan Cóndor, cuidadosamente elaborada para coordinar las políticas represivas en estos países. La circulación transatlántica del terror fue garantizada por el gobierno de los EEUU para preservar su poder y sus intereses económicos: todas las dictaduras implementaron reformas para transformar la economía desde un modelo de acumulación capitalista, basado en la exportación de materia prima desde la periferia a los centros industriales, a una economía de libre mercado. Esta estrategia fue primero puesta en práctica en España antes del fin de la Segunda Guerra Mundial. El gobierno norteamericano toleró las credenciales fascistas de Franco porque España tenía una posición crucial en una de las estrategias globales de la Guerra Fría, principalmente, el componente social y político dirigido en contra de las organizaciones populares con una orientación política nacional. La derrota de las masas populares fue vista como ventajosa para la inserción de España en los planes militares de EEUU. La aceptación de España en las Naciones Unidas en 1955 debería ser vista como la culminación de un largo proceso de negociación entre España y los EEUU, más que como el momento en que Franco 'abandonó' el fascismo. Durante la Guerra Fría, los EEUU aprendieron de España cómo usar a los dictadores fascistas para implementar reformas económicas y políticas impopulares sin tener que enfrentar la oposición de grupos militantes. Durante las décadas de los 70 y los 80 , este modelo fue 'perfeccionado' en el Cono Sur, transformándolo en un sistema de represión transnacional (Martín Cabrera). 


\section{Argentina}

La práctica de la desaparición forzada fue usada en todos los países del Cono Sur, pero fue en Argentina donde se implementó masiva y sistemáticamente. Es posible afirmar que la figura del desaparecido nació en Argentina, no solo porque los militares argentinos desarrollaron un sistema burocrático eficiente para hacer desaparecer un gran número de opositores, sino porque la gente que resistió el silencio del Estado preguntando dónde estaban los desaparecidos lograron crear un movimiento que originó estrategias que serían luego ampliamente difundidas en todo el mundo. Algunas de estas innovaciones son:

- Madres de Plaza de Mayo, el grupo emblemático de resistencia durante la dictadura y el proceso de transición se volvería un modelo para grupos de madres en numerosos países. Junto al grupo de madres y abuelas, un amplio y diverso conjunto de organizaciones de Derechos Humanos se desarrollaron en Argentina, incluyendo organizaciones como la Asamblea Permanente por los Derechos Humanos, el Centro de Estudios Legales y Sociales (CELS), Servicio Paz y Justica (SERPAJ), y el Movimiento Ecuménico por los Derechos Humanos (Brysk).

- Estos grupos buscaron identificar y nombrar el fenómeno de la desaparición forzada. La palabra 'desaparecido' no existía en ese entonces en el vocabulario de los Derechos Humanos. Los líderes en Derechos Humanos en Argentina fueron responsables de identificar, nombrar y denunciar la práctica sistemática de la desaparición forzada, y jugarían un rol crucial, primero, en redactar las declaraciones contra este crimen, y, posteriormente, en las convenciones regionales e internacionales que culminarían con la "Convención Internacional para la protección de todas las personas contra las desapariciones forzadas" de las Naciones Unidas firmada en 2006 (Sikkink).

- Los activistas argentinos ayudaron a crear el Grupo de Trabajo sobre Desapariciones Forzadas o Involuntarias de la ONU en 1980, el primer mecanismo de este tipo. Este mecanismo se volvería un instrumento esencial en el activismo por los Derechos Humanos en la ONU (Guest).

- Argentina inició la primera organización forense de Derechos Humanos en el mundo, el Equipo Argentino de Antropología Forense (EAAF) que sería luego instrumental en el trabajo en otros países, así como en entrenar a otros expertos y grupos en la temática.

- Argentina ha sido pionera en la temática, iniciando tres de las cuatro corrientes actuales en Justicia Transicional (truth commissions, domestic trials, and foreign trials) (Sikkink).

Basado en estos y otros elementos, Gabriel Gatti denomina a esta versión argentina el "desaparecido originario". El "desaparecido originario" vendría entonces a indicar ese lugar de condensación en el que confluyen instituciones —organizaciones de Derechos Humanos, el EAAF-, representaciones — las fotos, las siluetas-, leyes y convenciones —no porque allí se originen sino porque de allí emanan como impulso primordial—y, naturalmente, el nombre mismo o su formulación — tan temprana que incluso 
le correspondió a los perpetradores, Videla en este caso, proporcionar una de las definiciones más precisas del desaparecido al afirmar que "no está ni vivo ni muerto, es una incógnita, no tiene entidad, está desaparecido".

\section{España}

La transición española estuvo marcada por la Ley de Amnistía de 1977, que prohibía cualquier acción legal contra los que hubieran cometido violaciones a los Derechos Humanos durante la Guerra Civil y el Franquismo. El reporte general de la Comisión Interministerial para el estudio de la situación de las víctimas de la Guerra Civil y el Franquismo (2006) estima la existencia de entre 30.000 y 40.000 desaparecidos como consecuencia de la Guerra Civil. En 2000, asociaciones civiles tales como la Asociación para la Recuperación de la Memoria Histórica (ARMH) se dieron a localizar y exhumar fosas comunes con los restos de los republicanos ejecutados por el régimen franquista. Pero fue ciertamente el decreto del juez Baltasar Garzón del 16 de octubre de 2008, junto a la controversia mediática que suscitó, el que constituyó un punto de inflexión en la percepción del legado represivo del franquismo. En ese decreto, el juez Baltasar Garzón afirmaba que durante la Guerra Civil y el Franquismo se habían cometido graves violaciones a los derechos humanos, y esas violaciones eran equiparables a la categoría de crímenes de lesa humanidad. También sostenía que el procedimiento de desaparición forzada había sido utilizado sistemáticamente en España para ocultar la identificación de las víctimas e impedir que se realizara justicia hasta hoy. La traducción de la ley siguió, metafóricamente, un dispositivo tecnológico. El concepto fue "downloaded" y luego "uploaded" nuevamente al contexto local (Ferrándiz) para reconfigurar la memoria del régimen franquista. Aunque luego la Corte Superior de Justicia invalidara las demandas de Garzón, el debate público que se promovió alrededor de él transfirió exitosamente el término al debate español por la memoria. Como afirma Ferrándiz:

Beyond political to-ing and fro-ing, academic debates, legal blockages and media bulimia, the figure of forced disappearance has triumphed within the country's imaginary as a new symbolic anchor for the fusilados or paseados who were victims of the troops raised by Franco's dictatorship. (Ferrándiz 176)

Como lo muestra el caso de España, la figura del desaparecido se ha vuelto transnacional, un símbolo de la memoria transatlántica del terror, aun si las circunstancias históricas, políticas y sociales son diferentes en múltiples aspectos. Si la figura del desaparecido nació en Argentina, en España es posible observar como la figura fue - legal y simbólicamenteapropiada para renegociar el pasado franquista como una herramienta indispensable para apoyar las demandas políticas de las víctimas.

\section{México}

Desde el inicio de la Guerra contra el Narco en 2006, México experimentó una espiral de violencia que generó una grave crisis de derechos humanos en el país. Se estima que entre 
diciembre de 2006 y finales de 2015, más de 150.000 personas fueron asesinadas intencionalmente (Open Society Foundations 12), alrededor de 37.000 personas han desaparecido y alrededor de 300.000 han sido internamente desplazadas (Comisión Mexicana de Defensa y Promoción de los Derechos Humanos 2018). La estrategia principal del gobierno de incrementar la participación de las fuerzas armadas no tomó en cuenta las consecuencias que esto podía acarrear en la vulneración de los derechos humanos. Las violaciones a los derechos humanos — en particular el derecho a la integridad física - no fueron vistas como violaciones 'reales' de acuerdo a las normas de derechos humanos o capaces de atraer la atención internacional. De acuerdo a Anaya Muñoz México es un "hard case" para la globalización de los derechos humanos por dos razones. Primero, una gran proporción de las víctimas de la violencia están presuntamente involucradas en actividades criminales y por lo tanto difícilmente pueden ser percibidas como individuos vulnerables o inocentes, dignos de solidaridad y protección por parte de los actores internacionales. Segundo, el régimen de derechos humanos se basa en el principio de responsabilidad del Estado. En este caso los perpetradores directos son actores no estatales, concretamente, organizaciones criminales, o actores no estatales que actúan en colusión con el Estado. Este punto es particularmente problemático porque debe argumentarse de manera convincente que los brutales abusos cometidos por el crimen organizado implican una transgresión a los derechos humanos que involucra al Estado, lo que Hessbruegge (cit. en Anaya Muñoz 185) llama “diagonal obligations", es decir, la obligación del Estado de proteger a los ciudadanos de los actos perpetrados por actores no estatales. El supuesto involucramiento de las víctimas en actividades criminales (1) y la falta de pruebas de la participación directa del Estado como perpetrador (2) son las principales causas que dificultan enmarcar los asesinatos y desapariciones en México como efectivas violaciones a los derechos humanos. Las violaciones perpetradas por los cárteles son expuestas, abiertas: ejecuciones precedidas de tortura con los cadáveres expuestos en las calles. Aunque las desapariciones tienen lugar en un gran número, no son el único ni el principal método utilizado. Las desapariciones son juzgadas, en este sentido, como el resultado de un fallo de seguridad ("security failure" en palabras de Kenny y Serrano) y como la consecuencia del fracaso del Estado para investigar los crímenes. Los datos respecto a la impunidad revelan que entre principios del 2007 hasta 2012 solo se produjeron condenas en uno de cada diez casos de homicidio. Respecto a desapariciones forzadas, a febrero de 2015 solo se habían producido 313 investigaciones federales y solo 13 condenas (Open Society Foundations 12-13).

Pero el 26 de septiembre de 2014 se produjo un caso que representaría un punto de inflexión respecto a la situación de desapariciones en México: la desaparición de los 43 normalistas de Ayotzinapa. El 26 de septiembre de 2014, 43 estudiantes de la escuela Normal Raúl Isidro Burgos de Ayotzinapa, en México, desaparecieron. Habían viajado a Iguala para realizar un 'boteo' en preparación a la marcha por la masacre de Tlatelolco, cuando fueron interceptados por la policía. Policías de las tres fuerzas - municipales, estatales y federales - persiguieron a los estudiantes por horas, en diversos sitios, amenazándolos, disparándoles con armas de fuego, asesinando al menos a 9 personas, hiriendo a 40 y llevándose a 43 estudiantes, que aún permanecen desaparecidos. La desaparición de los estudiantes de Ayotzinapa ocasionó la crisis política más

${ }^{3}$ Número obtenido del Registro Nacional de Datos de Personas Extraviadas o Desaparecidas. Disponible en https://rnped.segob.gob.mx, consultado el 24 de julio de 2018. 
aguda de la última década en México. A diferencia de la relativa indiferencia de la comunidad internacional ante la situación del país, este caso resonó muy fuerte en la arena global e hizo que el término 'desaparición forzada' y 'desaparecidos' se impusiera en el discurso público. Las desapariciones de los estudiantes permitían iluminar, al mismo tiempo, la situación negada por la "niebla de la guerra" (Schedler).

Los 43 normalistas de Ayotzinapa son hoy un icono cuando se piensa en los desaparecidos en México, y lo son porque lo que lamentablemente les ocurrió refleja con claridad lo que miles de personas más han vivido desde que, en 2006, se declaró la guerra en contra del crimen organizado. (Franco Miguez 8)

Las desapariciones de los estudiantes de Ayotzinapa invirtieron la situación de desaparición forzada en el marco de la Guerra contra las Drogas que se imponía hasta el momento. Este caso puede ser efectivamente enmarcado como una violación de derechos humanos focalizándose en el tipo de violación, las víctimas y los perpetradores, y la impunidad: el tipo de violación implica la integridad física en la figura del desaparecido, las víctimas son estudiantes jóvenes no relacionados con actividades criminales, y por lo tanto individuos inocentes y vulnerables, y la responsabilidad del Estado está probada. Este encuadramiento del evento en el marco de las normas de derechos humanos permitió generar un proceso de presión internacional sobre México. Los procesos de activismo transnacional deben estar basados en evidencia, pero al mismo tiempo es crucial que los "hechos fríos" puedan ser traducidos en "shocking human histories" (Keck y Sikkink).

Tipificada como 'desaparición forzada', la desaparición de los 43 estudiantes activó una memoria transnacional de la desaparición propia de Latinoamérica, un repertorio de consignas, representaciones, narrativas y prácticas de resistencia en torno a la figura del desaparecido que contribuyó a proveer de inteligibilidad y sentido al fenómeno soslayado en el país. Al situar el caso de los 43 normalistas de Ayotzinapa en esta red de imágenes, representaciones, afectos y prácticas, las violaciones a los derechos humanos obtuvieron un marco claro, en el que el rol de los cárteles como perpetradores fue relegado a un segundo lugar mientras que el Estado era efectivamente señalado como el responsable principal de las violaciones.

La recuperación del 'tipo ideal' del desaparecido implica la activación de lo que Gabriel Gatti lista como dimensiones estéticas, psicoclínicas y político-sociales que incluyen el uso de las mismas consignas — "Vivos se los llevaron, vivos los queremos"—; los mismos tópicos psicoclínicos — "duelo inacabado", "ruptura de las cadenas filiatorias", "quiebra de la novela familiar"—; la movilización orientada al reclamo por la memoria y a la restitución de los cuerpos —el lema “¿Dónde están?”; el fuerte componente familista de la movilización congregada en torno a padres, madres y familiares de las víctimas; entre otros. Como ejemplo de la dimensión estética del 'desaparecido ideal' Gatti menciona el uso extendido de las fotos como representación del desaparecido, algo que permite seguir un recorrido que atraviesa los tres contextos y que permite observar cómo la representación mantiene sus rasgos originales al tiempo que cambia también en la traducción a otros espacios. 


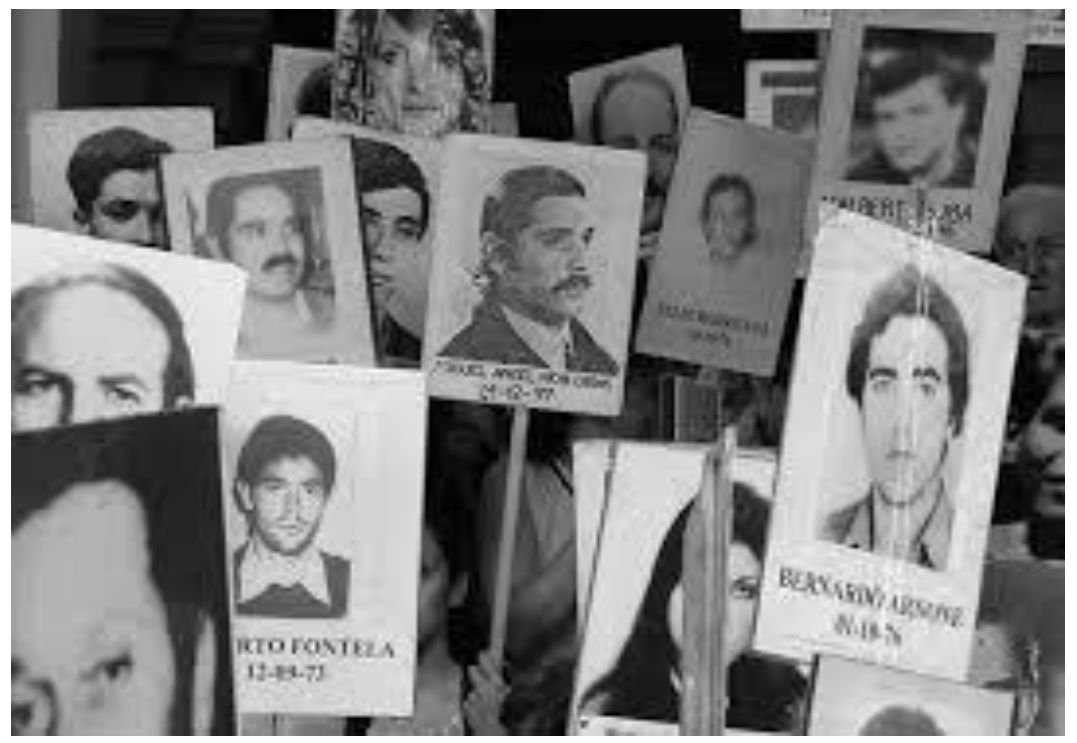

Argentina popularizó las fotos de las víctimas como modo de representar los cuerpos ausentes. Estas fotos fueron tomadas de los documentos de identidad, reproducidas en pancartas que eran portadas por los familiares en las protestas. Las fotos han sido usadas sin modificaciones hasta hoy como un símbolo: el original en su versión blanco y negro es respetado, manteniendo el sentido extendido de la fotografía como 'prueba' o 'documento' de lo real.

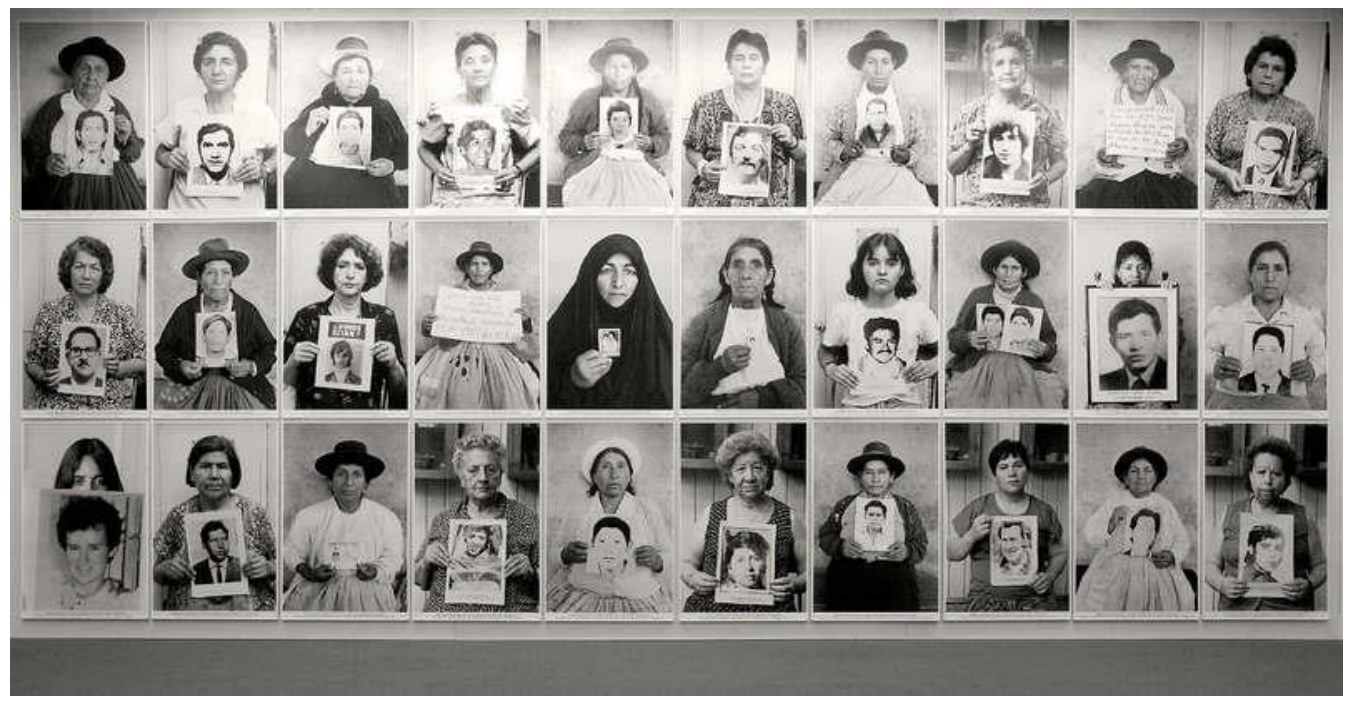

El fotógrafo español Gervasio Sánchez exhibió en 2011 “Desaparecidos”. La muestra sobre desaparición forzada fue presentada simultáneamente en tres ciudades de España. La exhibición, que retrata el fenómeno de la desaparición en 10 países (Guatemala, Chile, Argentina, Colombia, Iraq, El Salvador, Perú, Bosnia-Herzegovina y España) compartía la misma estructura narrativa y bloques temáticos y concluía con un significativo epílogo sobre la búsqueda y exhumación de los restos de víctimas de la Guerra Civil y el régimen franquista. Estas fotos estaban enraizadas en el símbolo ar- 
gentino pero la carga de la fotografía como 'documento' era reemplazada por el carácter 'estético', la dimensión artística de la pose y la estilización del dolor. La exhibición tuvo lugar en museos (Centro de Cultura Contemporánea de Barcelona) y fue presentada como una colección claramente transnacional.
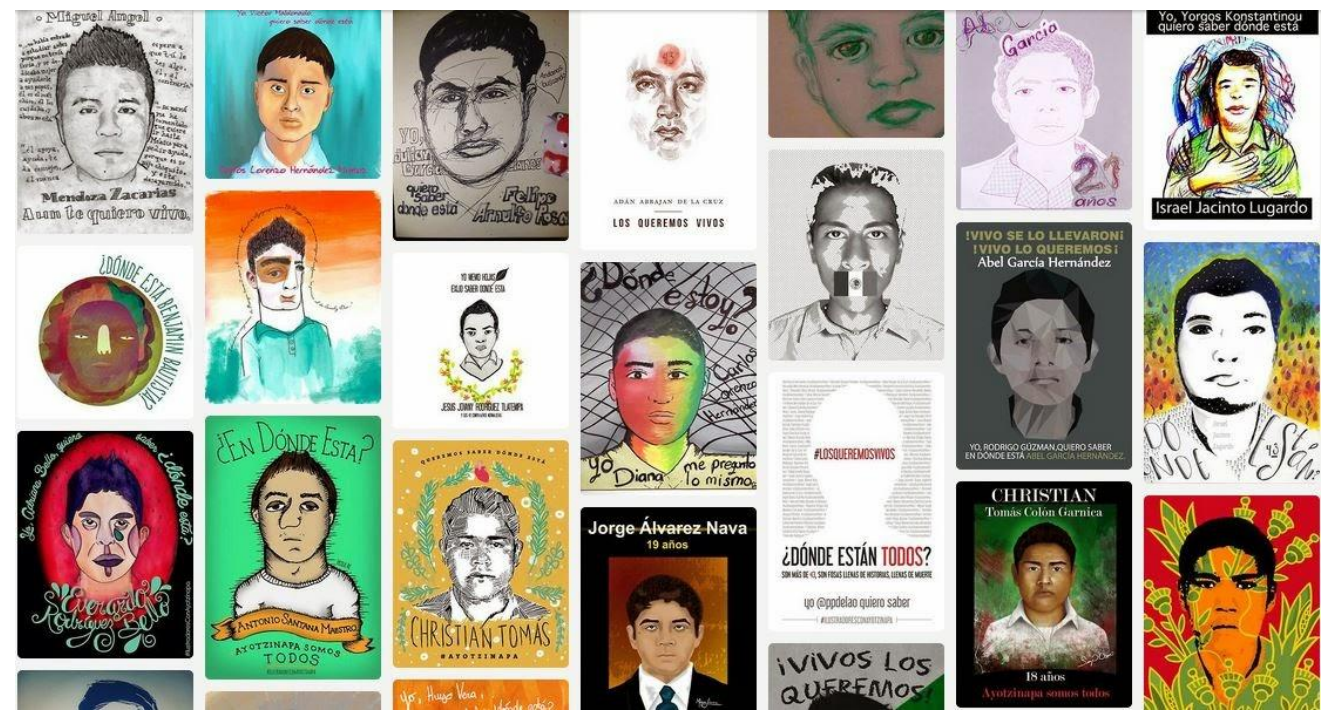

En México, las fotos de los estudiantes son también un recurso omnipresente para representar la desaparición. Pero en una de las representaciones más extendidas, la de "Ilustradores con Ayotzinapa", las fotos son transformadas en dibujos con la incorporación de la consigna 'Yo... quiero saber dónde está..." y 'exhibidas' en la web. Por lo tanto, no solo el escenario se transfiere desde la calle al museo, y del museo al espacio global, sino que las fotos son menos usadas como documentos de lo real que como objetos manipulados que construyen un sentido personal del evento para quienes lo dibujaron.

\section{Conclusión.}

\section{Sobre la exactitud histórica o el uso político del término 'desaparecido'}

Que el término ‘desaparecido’ fue utilizado en España y en México aplicado a contextos muy diferentes del argentino en el que se originó es un hecho. Lo que queda por debatir, o lo que se debate actualmente, es si ese uso es legítimo o no, adecuado o no, cuando se aplica a otras situaciones históricas caracterizadas por diferentes formas de ejercer la violencia. En un artículo reciente Elisabeth Anstett advierte, o mejor dicho, amonesta contra la transnacionalización del término, afirmando que

asimilar las víctimas de las juntas militares del Cono Sur con los muertos de la guerra civil española o del conflicto armado guatemalteco, y confundir la suerte de los detenidosdesaparecidos con el destino de las víctimas del franquismo o de los narcotraficantes mexicanos constituye $[\ldots]$ no solo un anacronismo histórico, sino también una confusión que perjudica el reconocimiento de la naturaleza particular de cada contexto. (Anstett 436-437) 
Anstett señala las numerosas divergencias entre los rasgos que caracterizaron a la violencia en Argentina en los 70 y cuyo resultado está inscripto en la matriz de la desaparición forzada, y el tipo de violencia que se ejerció en España y se ejerce en México. La desaparición en Argentina se llevó a cabo selectivamente, es decir, el objetivo a reprimir y aniquilar fue elegido, y lo prueba, por ejemplo, el número relativamente pequeño de víctimas en relación a la totalidad de población. En España y México, en cambio, la violencia tuvo - y tiene- un carácter indiscriminado. En ambos casos los números en relación a la población total vuelven a ser la prueba. Otra diferencia fundamental atañe al tratamiento que los cadáveres reciben: mientras en Argentina la norma fue el cuidadoso ocultamiento, al punto que aún hoy, y tras los numerosos esfuerzos de búsqueda solo se ha logrado encontrar un número muy reducido de restos, en México y en España no primó el objetivo de ocultarlos, sino que fueron tratados como restos, deshechos que se enterraban en fosas comunes sin ningún cuidado, fosas que pueden ser localizadas con relativa facilidad. Al carácter clandestino de la represión argentina se opone, además, el carácter

público, notorio, incluso a veces espectacular de los crímenes cometidos por los militares, los paramilitares, los policías o sus esbirros [...] la obscenidad de la violencia en las sociedades guatemalteca, mexicana o española, constituye incluso una herramienta de la acción guerrera, manejada de manera totalmente deliberada, que se inscribe en un registro antropológico propio de la búsqueda de trofeos (Anstett 528-532).

Luego de enumerar las diferencias radicales entre ambos contextos, Anstett concluye:

En definitiva, consideramos que esas exportaciones terminológicas - y las transferencias de capital simbólico que contienen - contribuyen a la lamentable instrumentalización de la voz de las víctimas, como señalaba Castillejo-Cuéllar (2005) en el contexto sudafricano, porque los muertos se han convertido realmente en bienes, en una red transnacional de prestigio. [...] Y si bien el intento de "consolarse con palabras", según la expresión de Flaubert, y hacer un uso amplio de la comparación con el caso de los desaparecidos latinoamericanos podría entenderse en el discurso militante, no puede, en cambio, ser válido en ciencias sociales, porque contribuye a sembrar confusión y a oscurecer, más que a aclarar, la situación, y porque es fruto de un abuso de lenguaje perjudicial para la construcción de una reflexión crítica. Es aún más grave: esta confusión puede convertirse en la base de futuros negacionismos, en el Cono Sur o en otras partes. En efecto —así lo ha demostrado la historiografía del Holocausto-, los intentos de falsear la historia se alimentan siempre de confusiones, omisiones e información parcial (Anstett 655-664).

Anstett cuestiona entonces que esta transnacionalización de la figura por parte de las Ciencias Sociales peca no sólo de inexactitud, lo que es decir, de ignorancia respecto a lo que se pretende estudiar, sino incluso de irresponsabilidad, al suponer que un tal uso podría conducir a algo tan grave como 'futuros negacionismos'. La comparación podría entenderse, concede, "en el discurso militante" pero resulta inadmisible en cambio en el discurso académico. Los argumentos de Anstett son exactos y convincentes cuando enumera cuidadosamente las divergencias entre el contexto mexicano de la Guerra contra el Narco y las dictaduras del Cono Sur. Sin embargo, hay un supuesto en su argumento que me parece discutible y es el hecho de que analizar la transnacio- 
nalización del término implique equiparar situaciones socio-políticas diferentes, aplanarlas por así decir, ignorar las divergencias. En algún punto este argumento asume que son los científicos sociales — sociólogos, politólogos, críticos literarios- quienes 'transnacionalizan' la aplicación cuando lo que en realidad hacen —o intentan haceres constatar esos usos y conjeturar un sentido. Si el uso del término 'desaparecido' aparece primero en el 'discurso militante' el fenómeno adquiere realmente relevancia cuando éste se expande y se propaga en el discurso social, abarcando un espectro que excede el marco de organizaciones de víctimas o de ONGs de derechos humanos, un espectro relativamente acotado. Aunque esto también depende de dónde trazamos el límite entre un discurso militante y uno que no lo es. En movimientos sociales con un alcance global como Ayotzinapa, todos los actores involucrados, desde las protestas tradicionales en el espacio público hasta la debatida participación política en la red, tienen un discurso militante. Cuando el término alcanza este nivel de propagación y penetración social, la pregunta por la especificidad histórica —_icuán exacto es el término? - da lugar a una pregunta por el sentido político — ¿por qué se lo usa y con qué sentido? Además, tampoco hace falta que aparezca la palabra como tal, sino que la figura del desaparecido se encarna, como decíamos, en todo un espectro de prácticas, narrativas y representaciones que la refieren sin nombrarla y en las que la transferencia de capital simbólico es aún mayor.

En el caso de México, las desapariciones de los 43 estudiantes de Ayotzinapa sí responden a la desaparición forzada tal como es definida legalmente en la Convención. A partir de este evento y a través de él, sin embargo, 'desaparición' y 'desaparecidos' se instalaron en el discurso social para reclamar por las víctimas soslayadas de la Guerra contra el Narco. La disputa no nació con Ayotzinapa. La desaparición forzada en México se remonta a la 'Guerra Sucia' iniciada en los 60 - desapariciones que pertenecen con pleno derecho a la categoría original - y se incrementan dramáticamente a partir del 2006, aunque el contexto de la Guerra contra el Narco sea otro, el de la "niebla de la guerra", como analiza Schedler en su libro. La disputa ya instalada antes de que sucediera Ayotzinapa, y que tuvo hitos tan importantes como el "Movimiento por la Paz con Justicia y Dignidad" liderado por Javier Sicilia en 2011, era por el reconocimiento de las víctimas. En este sentido, puede afirmarse que Ayotzinapa fue un punto crítico en ese largo reclamo, que dio a la disputa por las víctimas un argumento claro: el responsable es el Estado. La transnacionalización de la consigna "Vivos se los llevaron, vivos los queremos", que se originó en Argentina para contestar el intento de los militares de clausurar el conflicto dando por muertos a los desaparecidos, no es en México un simple anacronismo histórico, sino que reactiva - y da fuerza- al mismo reclamo. Se trata de demandar al Estado la información que no provee y la justicia que no brinda. De contestar el discurso de minimización patente en los 'daños colaterales' o en la 'verdad histórica' acerca de lo que sucedió en Ayotzinapa. Quienes lo esgrimen, lejos del peligro de incurrir en un futuro negacionismo, buscan, al contrario, impugnar un negacionismo presente, el del propio Estado.

En este sentido, la memoria transnacional como objeto de investigación puede brindarnos herramientas que iluminen —en lugar de oscurecer- la construcción de la memoria en el contexto contemporáneo que excede el marco del estado-nación sin dejar de ser éste la arena donde se libran las luchas. 


\section{Bibliografía}

Anaya Muñoz, Alejandro. "Non-state Actors as Violators in Mexico. A Hard Case for Global Human Rights Norms." The Politics of the Globalization of Law. Getting from Rights to Justice. Ed. Alison Brysk. New York: Routledge, 2013. 180-198.

Anstett, Élisabeth. "Comparación no es razón: a propósito de la exportación de las nociones de desaparición forzada y detenidos-desaparecidos." Desapariciones. Usos locales, circulaciones globales. Ed. Gabriel Gatti. Bogotá: Siglo del Hombre Editores, Universidad de los Andes, 2017. Kindle.

Antillón Najilís, Ximena y Paulina Vega González. Introducción a la Ley General de Victimas: Una herramienta para las víctimas y sus representantes. Ciudad de México: CCC/FUNDAR/SERAPAZ, 2014.

Appadurai, Arjun. Modernity at Large: Cultural Dimensions of Globalization. Minneapolis: University of Minnesota Press, 1996.

Assmann, Aleida y Sebastian Conrad (Ed.). Memory in a Global Age. Discourses, Practices and Trajectories. Basingstoke: Palgrave Macmillan, 2010.

Brysk, Alison. The Politics of Human Rights in Argentina. Protest, Change, and Democratization. Stanford: Stanford University Press, 1994.

Comisión Mexicana de Defensa y Promoción de los Derechos Humanos. "Episodios de Desplazamiento Interno Forzado Masivo en México.” Informe 2017, 2018. Web. 2 julio 2018.

Erll, Astrid. “Travelling Memory.” Parallax 17.4 (2011): 4-18.

Ezra, Elizabeth y Terry Rowden. "General introduction: what is transnational cinema?" Transnational cinema: the film reader. Ed. Elizabeth Ezra y Terry Rowden. New York: Routledge, 2006. 1-12.

Ferrándiz, Francisco. "De las fosas comunes a los derechos humanos: El descubrimiento de las desapariciones forzadas en la España contemporánea." Revista de Antropología Social 19 (2010): 161-189.

Franco Miguez, Darwin. "Prólogo. Ayotzinapa en la perspectiva nacional." Reflexiones sobre Ayotrinapa en la perspectiva nacional. Ed. Carmen Chinas Salazar y Jaime Preciado Coronado. Guadalajara: Universidad de Guadalajara, 2017.

Gatti, Gabriel. "Prolegómeno. Para un concepto científico de desaparición.” Desapariciones. Usos locales, circulaciones globales. Ed. Gabriel Gatti. Bogotá: Siglo del Hombre Editores, Universidad de los Andes, 2017. Kindle.

Guest, Iain. Behind the Disappearances: Argentina's Dirty War Against Human Rights and the United Nations. Philadelphia: University of Pennsylvania Press, 1990.

Hernández Borbolla, Manuel. "Peña y Calderón suman 234 mil muertos y 2017 es oficialmente el año más violento de la historia reciente de México.” Huffington Post México (23 noviembre 2017). Web. 2 julio 2018. 
Inglis, David. "Globalization and/of memory. On the complexification and contestation of memory cultures and practices." Routledge International Handbook of Memory Studies. Ed. Anna Lisa Tota y Trever Hagen. Oxon: Routledge, 2016. 143-157. Kindle.

Keck, Margaret E. y Kathryn Sikkink. Activism Beyond Borders: Advocacy Networks in International Politics. Ithaca: Cornell University Press, 1998.

Kenny, Paul and Mónica Serrano (Ed.). Mexicos Security Failure: Collapse into Criminal Violence. New York: Routlege, 2012.

Levy, Daniel y Natan Sznaider. The Holocaust and Memory in the Global Age. Translated by Assenka Oksiloff. Philadelphia: Temple University Press, 2006.

Martín Cabrera, Luis. Radical Justice: Spain and the Southern Cone Beyond Market and State. Lewisburg, PA: Bucknell University Press, 2011.

Open Society Foundations. Atrocidades innegables: confrontando crimenes de lesa bumanidad en México. New York: Open Society Foundations, 2016.

Reading, Anna. "Memory and Digital Media: Six Dynamics of the Globital Memory Field." On Media Memory. Collective Memory in a New Media Age. Ed. Motti Neiger, Oren Meyers y Eyal Zandberg. Basingstoke: Palgrave Macmillan, 2011. 241-252.

Rothberg, Michael. Multidirectional Memory: Remembering the Holocaust in the Age of Decolonization. Stanford: Stanford University Press, 2009.

Seigel, Micol. "Beyond Compare. Comparative Method after the Transnational Turn." Radical History Review 91 (2005): 62-90.

Schedler, Andreas. En la niebla de la guerra. Los ciudadanos ante la violencia criminal organirada. Mexico: CIDE, 2015. Kindle.

Sikkink, Kathryn. "From Pariah State to Global Protagonist: Argentina and the Struggle for International Human Rights." Latin American Politics and Society 50.1 (2008): $1-29$.

Tota, Anna Lisa y Trever Hagen. Routledge International Handbook of Memory Studies. Oxon: Routledge, 2016.

Vertovec, Steven. Transnationalism. Abingdon, New York: Routledge, 2009. 